\title{
The prognosis was poorer in colorectal cancers that expressed both VEGF and PROK1(No correlation coefficient between VEGF and PROK1)
}

\author{
Takanori Goi ${ }^{1}$, Toshiyuki Nakazawa ${ }^{1}$, Yasuo Hirono $^{1}$, Akio Yamaguchi ${ }^{1}$ \\ ${ }^{1}$ First Department of Surgery, University of Fukui, 9101193, Japan \\ Correspondence to: \\ Takanori Goi, e-mail: tgoi@u-fukui.ac.jp \\ Keywords: colorectal cancer, prokineticin 1 (PROK1), vascular endothelial growth factor (VEGF) \\ Received: May 25, $2015 \quad$ Accepted: July 17, $2015 \quad$ Published: July 30, 2015
}

\section{ABSTRACT}

The angiogenic proteins vascular endothelial growth factor (VEGF) and prokineticin 1 (PROK1) proteins are considered important in colorectal cancer, the relationship between their simultaneous expression and prognosis was investigated in the present study.

VEGF and PROK1 expression in 620 primary human colorectal cancer lesions was confirmed via immunohistochemical staining with anti-VEGF and anti-PROK1 antibodies, and the correlation between the expression of these 2 proteins and recurrence/prognosis were investigated.

VEGF protein was expressed in $329(53.1 \%)$ and PROK1 protein was expressed in $223(36.0 \%)$. PROK1 and VEGF were simultaneously expressed in $116(18.7 \%)$ of the 620 cases. The correlation coefficient between VEGF expression and PROK1 expression was $r=0.11$, and therefore correlation was not observed. Clinical pathology revealed that substantially lymphnode matastasis, hematogenous metastasis, or TMN advanced-stageIV was significantly more prevalent in cases that expressed both VEGF and PROK1 than in the cases negative for both proteins or those positive for only 1 of the proteins.

Also the cases positive for both proteins exhibited the worst recurrence and prognosis. In the Cox proportional hazards model, VEGF and PROK1 expression was an independent prognostic factor.

The prognosis was poorer in colorectal cancers that expressed both PROK1 and VEGF relative to the cases that expressed only 1 protein, and the expression of both proteins was found to be an independent prognostic factor.

\section{INTRODUCTION}

The therapeutic outcomes are relatively favorable for early-stage colorectal cancer but unsatisfactory for advanced (stage III/IV) cases, a phenomenon that requires further investigation [1]. Generally, the determining prognostic factor in colorectal cancer is hematogenous metastasis, including liver metastasis [1]. Elucidation of the metastatic mechanism is considered important and will provide the initial step toward the development of novel therapies.

Various molecular biological investigations of hematogenous mechanisms have revealed the following process in which angiogenic factors are closely involved during multiple steps [2-5]: cancer cells dissociate from the primary lesion, followed by basement membrane disintegration, movement within the interstitium, vascular invasion, and cancer cell adhesion, invasion, and proliferation in the target organ [6]. Oxygen and nutrition are supplied to tumor cells from the blood vessels and once the tumor has exceeded $1 \mathrm{~mm}$ in size, the blood vessels become hypoxic and angiogenesis becomes an absolute necessity [7, 8]. Cancer cells can directly produce angiogenic growth factors or proteases and release extracellular matrix (ECM)-bound vascular endothelial growth factor (VEGF) to stimulate the 
vessels and induce angiogenesis [9-10]. VEGF-A was identified as an angiogenic factor in 1989, and the family members VEGF-B, C, and D were subsequently isolated [11-13]. VEGF-A is a $45-\mathrm{kD}$ dimeric protein; in humans, VEGF121, VEGF165, VEGF189, and VEGF206 are produced via alternative splicing. In particular, VEGF165 is thought to be expressed in both healthy and tumor tissues [14-15]. In cancer tissues, VEGF165 correlates strongly with hematogenous metastasis in gastric cancer, colorectal cancer, lung cancer, and other malignant tumors [16-19]. The current National Comprehensive Cancer Network (NCCN) guidelines include anti-VEGF antibody therapy in addition to systemic FOLFOX (folinic acid/5-fluorouracil/oxaliplatin) and FOLFIRI (folinic acid/5-fluorouracil/irinotecan) chemotherapy for the treatment of unresectable/recurrent colorectal cancer [20].

Ferrara reported that Prokineticin 1 (PROK1) acts as a vascular endothelial growth factor in the adrenal gland, ovary, testis, and other endocrine tissues [21]. According to subsequent reports, the post-resection prognosis was significantly poorer for colorectal cancer patients with positive PROK1 mRNA expression than for PROK1-negative patients, and PROK1 protein was found to be involved in angiogenesis and lung metastasis from colorectal cancers $[22,23]$. According to recent findings, an anti-PROK1 antibody suppressed angiogenesis in a PROK1 receptor-expressing colorectal cancer subset, and the infiltrative ability of these cells was promoted by an autocrine PROK1 mechanism [24]. PROK1 expression also reportedly correlated with cancer progression and metastasis in pancreatic duct cancer, prostate cancer, neuroblastoma, and several other malignant tumors [25-28]. Therefore, PROK1 is a significant factor associated with tumor malignancy.

To date, individual angiogenic proteins have been investigated as important factors related to hematogenous metastasis in colorectal cancer; however, no study has evaluated 2 angiogenic proteins simultaneously. Accordingly, we examined both VEGF and PROK1, which have been independently correlated with the hematogenous metastasis of colorectal cancer, and obtained the interesting results reported below.

\section{RESULTS}

\section{VEGF and PROK1 protein expression in human colorectal cancer tissues}

The Fig. 1A shows representative cases of positive expression in primary human colorectal cancer lesions. VEGF expression was observed in 329 (53.1\%) of the 620 cases, whereas PROK1 was expressed in $223(36.0 \%)$ of the 620 cases.

\section{The relationship between VEGF expression and PROK1 expression in human colorectal cancer tissues}

Neither VEGF nor PROK1 was expressed in 184 $(29.7 \%)$ of the 620 cases. VEGF alone was expressed in $213(34.4 \%)$ of the 620 cases, and PROK1 alone was expressed in $107(17.3 \%)$ of the cases. Both proteins were expressed in $116(18.7 \%)$ of the 620 cases(Fig. 1B). The correlation coefficient between VEGF expression and PROK1 expression was $r=0.11$, and therefore correlation was not observed(Fig. 1C).

\section{The relationship between PROK1/VEGF expression in human colorectal cancer tissues and the survival rate}

The 5-year survival rates for all colorectal cancer patients were $91.3 \%$ among cases with no VEGF/PROK1 expression, 76.4\% among cases that expressed either protein, and $57.3 \%$ among cases that expressed both proteins; the latter rate indicated a significantly poorer prognosis(Fig. 1D).

\section{The relationship between PROK1 and VEGF protein expression and clinicopathologic factors}

An investigation of the relationship between VEGF/ PROK1 protein expression and clinicopathological factors revealed that the group that expressed either of the angiogenic proteins included a significantly greater number of cases with a substantially lymphnode metastasis and hematogenous metastasis(TMN advanced-stage III, IV) relative to the group lacking the expression of both proteins. Furthermore, the group that expressed both proteins had a significantly greater number of cases with lymphnode metastasis, hematogenous metastasis, and TMN advanced-stageIV tumors relative to the other 2 groups. No relationships were found with respect to gender, age, histological type, histological type, lymphatic invasion, venous invasion, and peritoneal metastasis(Table 1).

\section{The relationship between both PROK1 and VEGF proteins expression and the hematogenous metastatic recurrence rate according to the colorectal cancer stage}

Among stage III colorectal cancers, the hematogenous metastatic recurrence rates were $11.3 \%$ among cases with no expression of the 2 proteins, $24.6 \%$ among cases that expressed either protein, and $34.1 \%$, a significant increase, among cases that expressed both proteins(Table 2). Among stage I and II cancers, no significant differences were observed in the hematogenous 
(A)-1)

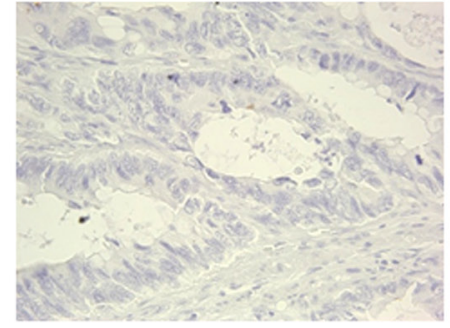

(A)-2) VEGFstain (-)

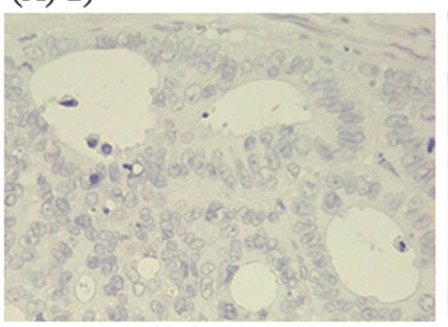

PROK1 stain (-)

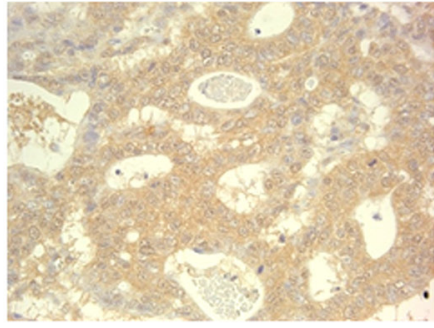

VEGFstain $(+)$

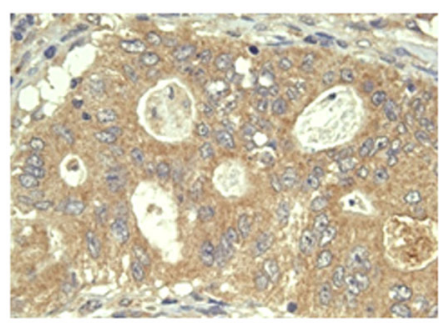

PROK1 stain $(+)$

(B)

\begin{tabular}{|c|c|c|c|}
\hline & & \multicolumn{2}{|c|}{ VEGF } \\
\hline & & - & + \\
\hline \multirow{2}{*}{ PROKl } & - & $184(29.7 \%)$ & $213(34.4 \%)$ \\
\hline & + & $107(17.3 \%))$ & $116(18.7 \%)$ \\
\hline
\end{tabular}

(C)

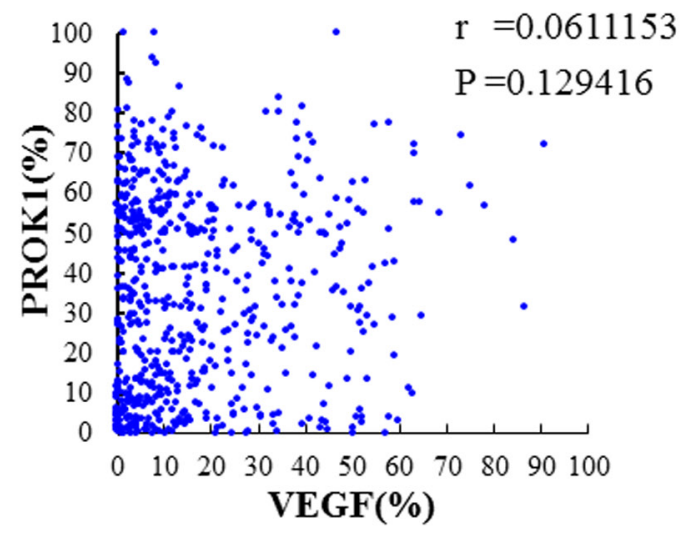

(D)

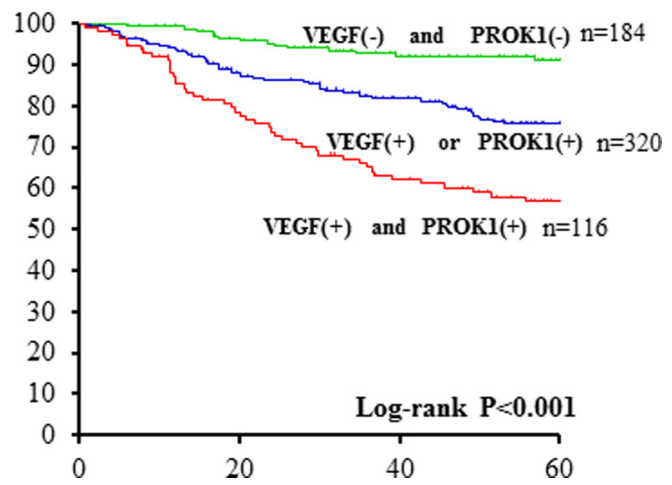

Figure 1: A-1. Immunohistochemical staining with anti-VEGF mAb Left: VEGF expression was not detected inprimary colorectal cancer lesion. Right: VEGF expression was detected in primary colorectal cancer lesions. A-2. Immunohistochemical staining with anti-PROK1 mAb Left: PROK1 expression was not detected inprimary colorectal cancer lesion. Right: PROK1 expression was detected in primary colorectal cancer lesions. B. The relationship between VEGF expression and PROK1 expression in sporadic 620 patients with primary colorectal cancer VEGF expression was observed in $325(52.5 \%)$ of the 620 cases, whereas PROK1 was expressed in $223(36.0 \%)$ of the 620 cases. Neither VEGF nor PROK1 was expressed in $184(30.1 \%)$ of the 620 cases. Both proteins were expressed in $115(18.6 \%)$ of the 620 cases VEGF alone was expressed in $210(33.9 \%)$ of the 620 cases, and PROK1 alone was expressed in 108 (17.4\%) of the cases. C. The correlation between VEGF expression and PROK1 expression The correlation coefficient between VEGF expression and PROK1 expression was $r=0.11$. Correlation was not observed. D. Relationship between PROK1/ VEGF expression and survival rate in colorectal cancer patients. The 5 -year survival rate was $91.3 \%$ in the colorectal cancer patients with expression of neither VEGF nor PROK1, 76.4\% with expression of either VEGF or PROK1; and 57.3\% with expression of both VEGF and PROK1.

metastatic recurrence rates among the groups that did and did not express VEGF and/or PROK1.

\section{The relationship between both PROK1 and VEGF expression in human colorectal cancer tissues and the survival rate}

The 5-year survival rates for Stage III colorectal cancer patients were $84.4 \%$ among cases that expressed either VEGF or PROK1 protein, and $59.1 \%$ among cases that expressed both proteins(Fig. 2C). For Stage IV colorectal cancer patients, the 5-year survival rate was $16.1 \%$ among cases that expressed either VEGF or
PROK1 protein and 5.1\% among cases that expressed both proteins(Fig. 2D). Therefore, for both stages, the survival rates were significantly lower in cases with both PROK1 and VEGF expression. No significant differences in survival were observed between patients with Stage I and Stage II colorectal cancer in terms of both VEGF and PROK1 expression in the primary lesions(Fig. 2A, 2B).

\section{Prognostic factors in colorectal cancer patients}

The univariate analysis, conducted according to a Cox proportional hazards model, revealed that both PROK1 and VEGF protein expression, histological type, 
Table 1: Correlation between clinicopathologic features and VEGF and PROK1 expression

\begin{tabular}{|c|c|c|c|c|c|}
\hline & & $\begin{array}{c}\text { VEGF and } \\
\text { PROK1 }\end{array}$ & $\begin{array}{l}\text { VEGF or } \\
\text { PROK1 }\end{array}$ & $\begin{array}{c}\text { VEGF and } \\
\text { PROK } 1\end{array}$ & \\
\hline & Total & $\begin{array}{c}\text { No. of negative } \\
\text { cases }\end{array}$ & $\begin{array}{c}\text { No. of positive } \\
\text { cases }\end{array}$ & $\begin{array}{c}\text { No. of positive } \\
\text { cases }\end{array}$ & $P$-value \\
\hline All cases & 620 & 184 & 320 & 116 & \\
\hline Gender & & & & & 0.740 \\
\hline Male & 365 & 107 & 186 & 72 & \\
\hline Female & 255 & 77 & 134 & 44 & \\
\hline Age (average 66.5) & & & & & 0.962 \\
\hline$<55$ & 108 & 31 & 6 & 21 & \\
\hline$凶 55$ to $<65$ & 143 & 39 & 74 & 30 & \\
\hline$\triangle 65$ to $<75$ & 187 & 57 & 95 & 35 & \\
\hline 凶75 & 182 & 57 & 95 & 30 & \\
\hline Histological type & & & & & 0.313 \\
\hline Well+Mode & 572 & $168(91.4 \%)$ & $300(93.8 \%)$ & $104(89.7 \%)$ & \\
\hline Poor & 28 & $8(4.3 \%)$ & $11(3.4 \%)$ & $9(7.8 \%)$ & \\
\hline Mucinous & 20 & $8(4.3 \%)$ & $9(2.8 \%)$ & $3(2.5 \%)$ & \\
\hline Serosal invasion & & & & & 0.067 \\
\hline Negative & 148 & $55(29.9 \%)$ & $70(21.9 \%)$ & $23(19.8 \%)$ & \\
\hline Positive & 472 & $129(70.1 \%)$ & $250(78.1 \%)$ & $93(80.2 \%)$ & \\
\hline Lymphatic invasion & & & & & 0.007 \\
\hline Negative & 99 & $42(22.8 \%)$ & $39(12.2 \%)$ & $18(15.5 \%)$ & \\
\hline Positive & 521 & $142(77.2 \%)$ & $281(87.8 \%)$ & $98(84.5 \%)$ & \\
\hline Venous invasion & & & & & 0.946 \\
\hline Negative & 244 & $74(40.2 \%)$ & $124(38.7 \%)$ & $46(39.7 \%)$ & \\
\hline Positive & 376 & $110(59.8 \%)$ & $196(61.3 \%)$ & $70(60.3 \%)$ & \\
\hline Peritoneal metastasis & & & & & 0.330 \\
\hline Negative & 600 & $181(98.4 \%)$ & $308(96.2 \%)$ & $111(95.7 \%)$ & \\
\hline Positive & 20 & $3(1.6 \%)$ & $12(3.8 \%)$ & $5(4.3 \%)$ & \\
\hline Hematogenous Metastasis & & & & & $<0.001$ \\
\hline Negative & 560 & $178(96.7 \%)$ & $293(91.6 \%)$ & $89(76.7 \%)$ & \\
\hline \multirow[t]{2}{*}{ Positive } & 60 & $6(3.3 \%)$ & $27(8.4 \%)$ & $27(23.3 \%)$ & \\
\hline & & \multicolumn{3}{|c|}{$p=0.024$} & \\
\hline T(TNM 6th) & & & & & 0.067 \\
\hline $\mathrm{T} 1-2$ & 148 & $55(29.9 \%)$ & $70(21.9 \%)$ & $23(19.8 \%)$ & \\
\hline $\mathrm{T} 3-4$ & 472 & $129(70.1 \%)$ & $250(78.1 \%)$ & $93(80.2 \%)$ & \\
\hline N(TNM 6th) & & & & & $<0.001$ \\
\hline
\end{tabular}

(Continued) 


\begin{tabular}{|c|c|c|c|c|c|}
\hline & & $\begin{array}{l}\text { VEGF and } \\
\text { PROK1 }\end{array}$ & $\begin{array}{l}\text { VEGF or } \\
\text { PROK1 }\end{array}$ & $\begin{array}{l}\text { VEGF and } \\
\text { PROK } 1\end{array}$ & \\
\hline & Total & $\begin{array}{c}\text { No. of negative } \\
\text { cases }\end{array}$ & $\begin{array}{l}\text { No. of positive } \\
\text { cases }\end{array}$ & $\begin{array}{c}\text { No. of positive } \\
\text { cases }\end{array}$ & $P$-value \\
\hline N0 & 330 & $121(65.8 \%)$ & $164(51.3 \%)$ & $45(38.8 \%)$ & \\
\hline \multirow[t]{2}{*}{$\mathrm{N} 1-2$} & 290 & $63(34.2 \%)$ & $156(48.7 \%)$ & $71(61.2 \%)$ & \\
\hline & & \multicolumn{3}{|c|}{$p=0.021$} & \\
\hline Stage(TNM 6th) & & & & & $<0.001$ \\
\hline I & 117 & $49(26.6 \%)$ & $53(16.6 \%)$ & $15(12.9 \%)$ & \\
\hline II A & 114 & $40(21.8 \%)$ & $58(18.1 \%)$ & $16(13.8 \%)$ & \\
\hline II B & 85 & $35(19.0 \%)$ & $42(13.1 \%)$ & $8(6.9 \%)$ & \\
\hline III A & 19 & $5(2.7 \%)$ & $10(3.1 \%)$ & $4(3.4 \%)$ & \\
\hline III B & 130 & $30(16.3 \%)$ & $77(24.1 \%)$ & $23(19.8 \%)$ & \\
\hline III C & 74 & $18(9.8 \%)$ & $39(12.2 \%)$ & $17(14.7 \%)$ & \\
\hline \multirow[t]{2}{*}{ IV } & 81 & $7(3.8 \%)$ & $41(12.8 \%)$ & $33(28.5 \%)$ & \\
\hline & & \multicolumn{2}{|c|}{$P<0.001$} & .001 & \\
\hline
\end{tabular}

Well, well differentiated adenocarcinoma; Mode, moderately differentiated adenocarcinoma; Poor, poorly differentiated adenocarcinoma; Muc, mucinous adenocarcinoma.

Table 2: Recurrence rate of hematogenous metastasis according to VEGF and PROK 1 expression in each stage of colorectal cancers

\begin{tabular}{|c|c|c|c|c|c|c|c|c|}
\hline & \multicolumn{2}{|c|}{ VEGF, PROK1 } & \multicolumn{2}{|c|}{ VEGF or PROK1 } & \multicolumn{3}{|c|}{ VEGF and PROK1 } & \\
\hline Stage & \multicolumn{2}{|c|}{ negative } & \multicolumn{2}{|c|}{ positive } & \multicolumn{3}{|c|}{ positive } & \\
\hline \multirow[t]{2}{*}{ Grouping } & \multicolumn{2}{|c|}{ cases recurrence $(\%)$} & \multicolumn{2}{|c|}{ cases recurrence(\%) } & \multicolumn{3}{|c|}{ cases recurrence(\%) } & $\boldsymbol{P}$ \\
\hline & 177 & $12(6.8 \%)$ & 279 & $44(15.8 \%)$ & 83 & 19 & $(22.9 \%)$ & 0.001 \\
\hline I & 49 & $2(4.1 \%)$ & 53 & $2(3.8 \%)$ & 15 & 1 & $(6.7 \%)$ & 0.884 \\
\hline II & 75 & $4(5.3 \%)$ & 100 & $11(11 \%)$ & 24 & 3 & $(12.5 \%)$ & 0.369 \\
\hline III & 53 & $6(11.3 \%)$ & 126 & $31(24.6 \%)$ & 44 & 15 & $(34.1 \%)$ & 0.027 \\
\hline
\end{tabular}

serosal invasion, lymphatic invasion, venous invasion, lymphnode metastasis, peritoneal metastasis, and hematogenous metastasis were factors that significantly correlated with prognosis. The multivariate analysis indicated that both VEGF and PROK1 protein expression, histological type, serosal invasion, lymphnode metastasis, and hematogenous metastasis were independent prognostic factors. The hazard ratio for VEGF/PROK1 protein expression was 2.317 (Table 3 ).

\section{DISCUSSION}

In recent years, gastrointestinal cancer and other various malignant tumors have been investigated via molecular biological techniques, and a considerable number of genes are thought to be involved in the metastatic and growth mechanisms [29, 30]. In particular, a number of reports have implicated angiogenic growth factor involvement in hematogenous metastasis, the significance of which is apparently considerable $[31,32]$. Among various gastrointestinal tumors, the most well known VEGF was found to correlate with the hematogenous metastasis of gastric and colorectal cancers [16-18], and elevated VEGF expression induced angiogenesis near the tumor. Furthermore, increased VEGF expression was reported to be a poor prognostic factor for colorectal cancer, among other cancers.

Although the PROK1 protein investigated in the present study was identified as an angiogenic factor in endocrine cells by Ferrara [21], the researchers observed its involvement in the hematogenous metastasis and autocrine mechanism-based invasive ability of human 

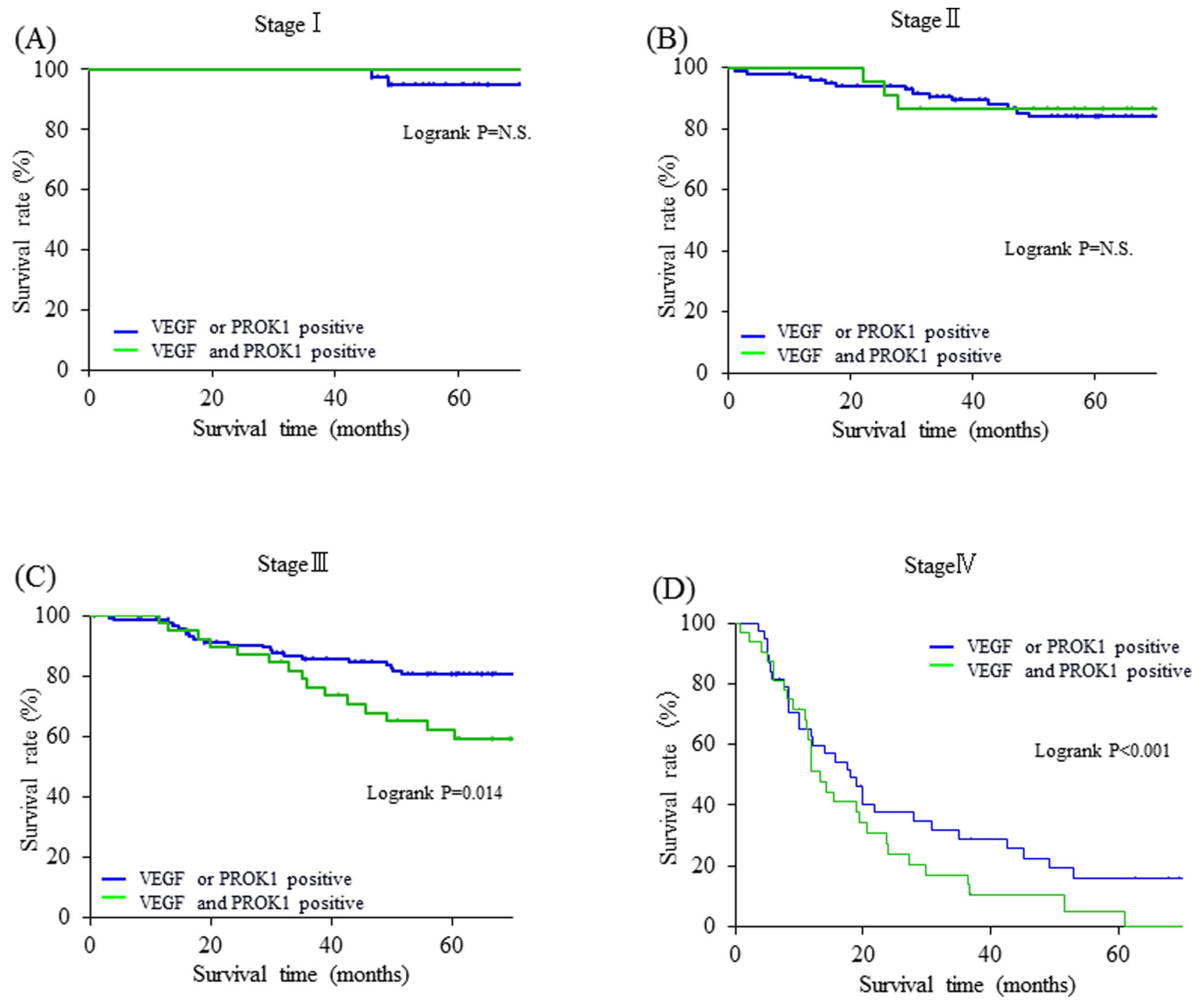

Figure 2: Relationship between the expression of VEGF/PROK1 protein and survival rates in colorectal cancer patients. A. Stage I. B. Stage II. C. Stage III. D. Stage IV. For Stage III and Stage IV colorectal cancer patients, Patients with both VEGF and PROK1 expressions tumors had significantly poorer prognosis than those with either VEGF or PROK1 expression tumors.

colorectal cancer cells, and its significance in various malignant tumors was demonstrated via its relationship with malignancy in prostate cancer, neuroblastoma, and pancreatic duct cancer [25-28]. Cancer cell growth or progression is considered consequent to the overexpression or deficiency of various factors and, as mentioned earlier, no reports have been published on the simultaneous investigation of VEGF and PROK1, both of which are substantially involved in the hematogenous metastasis of colorectal cancer. Therefore, the simultaneous investigation of these 2 factors is significant.

According to the study results, both PROK1 and VEGF were expressed in approximately $20 \%$ of the tumors, either PROK1 or VEGF in approximately $50 \%$, and neither factor in approximately 30\%. Clinicopathologically, both PROK1 and VEGF expression relative to the groups lacking the expression of both proteins or either VEGF or PROK1 protein increased significantly in the cases with positive lymph node metastasis, positive hematogenous metastasis, and advanced-stage tumors, suggesting an association between these 2 proteins and malignancy. Furthermore, the recurrence rate was significantly higher when both proteins were expressed in the primary lesions of stage III colorectal cancer patients with a high risk of recurrence when compared with other cases. The prognosis of patients who expressed both proteins was also significantly poorer, thus reflecting the recurrence rate. These 2 proteins are considered important in light of their close relationships with human colorectal cancer metastasis and recurrence.

Regarding the VEGF signaling pathway, VEGF binds to 2 receptors on the cell surface, VEGFR-1 and VEGFR-2, although VEGF signaling primarily acts via VEGFR-2 [33-35]. A dimer forms upon VEGF binding to 
Table 3: Pathological findings and PROK1/VEGF as prognostic factor for colorectal cancer patients

Univariate analysis

$\begin{array}{cccc}\begin{array}{c}\text { Hazard } \\ \text { Ratio }\end{array} & 95 \% \text { CI } & P \text {-value } & \begin{array}{c}\text { Hazard } \\ \text { Ratio }\end{array}\end{array}$

\begin{tabular}{|l|l|l|l|l|l|l|}
\hline Gender & 0.735 & $0.520-1.041$ & 0.083 & & & \\
\hline Age & 0.999 & $0.985-1.013$ & 0.589 & & & \\
\hline PROK1+VEGF & 3.316 & $2.364-4.652$ & 0.000 & 2.317 & $1.618-3.317$ & 0.000 \\
\hline Histological type & 2.168 & $1.669-2.816$ & 0.000 & 2.091 & $1.583-2.761$ & 0.000 \\
\hline
\end{tabular}

$\left(\right.$ Well $^{a}+$ Mode $^{\mathrm{b}} /$ Poor $\left.^{\mathrm{c}} / \mathrm{Muc}^{\mathrm{d}}\right)$

\begin{tabular}{|l|c|c|c|c|c|c|}
\hline Serosal invasion & 5.931 & $2.905-12.107$ & 0.000 & 3.758 & $1.666-8.479$ & 0.001 \\
\hline Lymphatic invasion & 3.057 & $1.556-6.008$ & 0.001 & 1.181 & $0.570-2.448$ & 0.655 \\
\hline Venous invasion & 1.736 & $1.209-2.493$ & 0.003 & 0.973 & $0.657-1.440$ & 0.891 \\
\hline Lymphnode metastasis & 3.193 & $2.221-4.592$ & 0.000 & 1.686 & $1.141-2.490$ & 0.009 \\
\hline Peritoneal metastasis & 5.001 & $2.754-9.080$ & 0.000 & 1.097 & $0.579-2.078$ & 0.776 \\
\hline Hematogenous & 13.544 & $9.439-19.434$ & 0.000 & 8.808 & $5.883-13.189$ & 0.000 \\
\hline Metastasis & & & & & & \\
\hline
\end{tabular}

${ }^{a}$ Well, well differentiated adenocarcinoma

${ }^{\mathrm{b}}$ Mode, moderately differentiated adenocarcinoma

'Poor, poorly differentiated adenocarcinoma

${ }^{\mathrm{d}}$ Muc, mucinous adenocarcinoma.

VEGFR -1 or VEGFR-2, and after autophosphorylation, a cell proliferation-promoting signal is transmitted to the nucleus via a mitogen-activated protein kinase (MAPK) signaling cascade [36]. As a result, angiogenesis occurs and cancer cells use the supplied nutrition and oxygen to support further growth.

Meanwhile, PROK1 signals through the G-proteincoupled receptors prokineticin receptor-1 (PROKR1) and prokineticin receptor-2 (PROKR2) and activates the downstream processes of intracellular calcium flux, p44/p42 MAPK phosphorylation, and the serinethreonine kinase Akt to mediate cellular function [37]. Overall, PROK1 is considered an important factor in cell proliferation, anti-apoptosis, differentiation, and cellular kinetics regulation.

As discussed above, VEGF and PROK1 induce angiogenesis via different cellular signaling pathways that initiate from different receptors. Therefore, these proteins are likely to have different functions. According to the results of a multivariate analysis based on a Cox proportional hazards model, the expression of both PROK1 and VEGF was found to be an independent prognosis factor.

In human colorectal cancers, PROK1 and VEGF are important factors for invasion and metastasis. The combined expression of both proteins comprises a significant prognosis factor, as the prognosis was poor when both proteins were expressed.
These factors are considered to be a good indicator for recurrence rate and prognosis. Also it is expected that the prognosis will be improved for patients that expressed both PROK1 and VEGF by treating chemotherapy and additional therapeutics.

\section{MATERIALS AND METHODS}

\section{Patients and samples}

Surgical specimens and adjacent normal colorectal tissues were obtained from sporadic 620 patients with primary colorectal cancer. Patients who had undergone surgery for primary colorectal cancer at the First Department of Surgery, University of Fukui, Japan between 1990 and 2007, were studied. Tumors were staged according to the TMN classification [38], 117, 199, 223, and 81 were I, II, III, and IV respectively. Histopathological and prognostic findings were evaluated by two pathologists based upon internationally established criteria. Surgical specimens were fixed in $10 \%$ paraformaldehyde( $\mathrm{pH} 6.8$ ) for $24 \mathrm{~h}$, and embedded in paraffin.

The eligibility criteria were as follows: (i) a histopathological findings confirmed primary colorectal cancer, (ii) resection of colorectal cancer with extended (D2 or D3) lymphnode dissection [39], (iii) histological curative resection(StageI III), (iv) an Eastern 
Cooperative Oncology Group performance status(PS) of 0 or 1 , (v) no chemotherapy or radiotherapy before surgical resection, (vi) Patients with stage III/IV received 5-fluorouracil-based chemotherapy after surgical resection, (vii) Patients with stage I/II received no chemotherapy after surgical resection, (viii) All patients were followed up for recurrence at regular intervals for five years, underwent chest X-ray, computed tomography, and colonoscopy.

\section{Immunohistochemical study}

Paraffin sections were cut $4 \mu \mathrm{m}$ thick and deparaffinized with xylene. Deparaffinied sections were incubated with $1 \%$ hydrogen peroxidase in methanol for 30 minites. The slides were incubated with antiPROK1 mAb [40] and anti-VEGF mAb(Santa Cruz Biotechnology, USA) for 1 hour. After washing with TBS, staining was analyzed by using for the ChemMate method(Dako, Denmark). Counterstaining was performed with hematoxylin. We decided the cut-off more than $30 \%$ of the tumor cells this time. Also we decided the cut-off more than $10 \%$ of the tumor cells for VEGF expression. Histopathological diagnosis was evaluated by two pathologists.

\section{Statistical-analysis}

The statistical significance was determined by the $\chi^{2}$ test or student $t$-test using Stat Mate IV(ATMS Co., Ltd., Japan).

Survival curves of the patients was performed using the Kaplan-Meier technique. The outcomes from different groups of patients were compared by log rank test using Stat Mate IV(ATMS Co., Ltd., Japan).

The multivariate analysis for patient prognosis was determined by Cox proportional hazards model using SPSS soft ware(IBMM SPSS Statistics, IBM Corporation, USA).Differences were considered significant at $P$ values less than .05 .

\section{ACKNOWLEDGMENTS AND FUNDING}

The technical assistance of Ms Saitoh M with this research was appreciated.

This work was supported in part by a Grant-in-Aid for Science Research $(C)$ from the Ministry of Education, Sports, Science and Technology of Japan (No.25462047).

\section{DISCLOSURE OF POTENTIAL CONFLICTS OF INTERESTS}

No potential conflicts of interests were disclosed.

\section{Authors' declaration}

All the authors have read the manuscript and have approved this submission.

We attest that the research was performed in accordance with the humane and ethical rules for human experimentation that are stated in the Declaration of Helsinki. The article is original, is not under consideration by any other journal and has not previously been published.

\section{Ethics}

The procedures of our study received ethical approval with institutional committee responsible for human experimentation at university of Fukui and all those who participated in our study did so voluntarily, having given their informed consent.

\section{REFERENCES}

1. Watanabe T, Itabashi M, Shimada Y, Tanaka S, Ito Y, Ajioka Y, Hamaguchi T, Hyodo I, Igarashi M, Ishida H, Ishihara S, Ishiguro M, Kanemitsu Y, et al. Japanese Society for Cancer of the Colon and Rectum (JSCCR) Guidelines 2014 for treatment of colorectal cancer. Int J Clin Oncol. 2015; 20:207-239.

2. Ferrara N. Pathways mediating VEGF-independent tumor angiogenesis. Cytokine Growth Factor Rev. 2010; 21:21-26.

3. Rmali KA, Puntis MC, Jiang WG. Tumour-associated angiogenesis in human colorectal cancer. Colorectal Dis. 2007; 9:3-14.

4. Kamba T, McDonald DM. Mechanisms of adverse effects of anti-VEGF therapy for cancer. Br J Cancer. 2007; 6:1788-1795.

5. Bose D, Meric-Bernstam F, Hofstetter W, Reardon DA, Flaherty KT, Ellis LM. Vascular endothelial growth factor targeted therapy in the perioperative setting: implications for patient care. Lancet Oncol. 2010; 11:373-382.

6. Hanahan D, Folkman J. Patterns and emerging mechanisms of the angiogenic switch during tumorigenesis. Cell. 1996; 86:353-364.

7. Avraamides CJ, Garmy-Susini B, Varner JA. Integrins in angiogenesis and lymphangiogenesis. Nat Rev Cancer. 2008; 8:604-617.

8. Folkman J. Seminars in Medicine of the Beth Israel Hospital, Clinical applications of research on angiogenesis. N Engl J Med. 1995; 333:1757-1763.

9. Ghosh S, Basu M, Roy SS. ETS-1 protein regulates vascular endothelial growth factor-induced matrix metalloproteinase- 9 and matrix metalloproteinase- 13 expression in 
human ovarian carcinoma cell line SKOV-3. J Biol Chem. 2012; 287:15001-15015.

10. Heo SH, Choi YJ, Ryoo HM, Cho JY. Expression profiling of ETS and MMP factors in VEGF-activated endothelial cells: role of MMP-10 in VEGF-induced angiogenesis. J Cell Physiol. 2010; 224:734-742.

11. Joukov V, Sorsa T, Kumar V, Jeltsch M, ClaessonWelsh L, Cao Y, Saksela O, Kalkkinen N, Alitalo K. Proteolytic processing regulates receptor specificity and activity of VEGF-C. EMBO J. 1997; 16:3898-3911.

12. Stacker SA, Stenvers K, Caesar C, Vitali A, Domagala T, Nice E, Roufail S, Simpson RJ, Moritz R, Karpanen T, Alitalo K, Achen MG. Biosynthesis of vascular endothelial growth factor-D involves proteolytic processing which generates non-covalent homodimers. J Biol Chem. 1999; 274:32127-32136.

13. Li X, Tjwa M, Van Hove I, Enholm B, Neven E, Paavonen K, Jeltsch M, Juan TD, Sievers RE, Chorianopoulos E, Wada H, Vanwildemeersch M, Noel A, et al. Arterioscler Reevaluation of the role of VEGF-B suggests a restricted role in the revascularization of the ischemic myocardium. Thromb Vasc Biol. 2008; 28:1614-1620.

14. Houck KA, Ferrara N, Winer J, Cachianes G, Li B, Leung DW. The vascular endothelial growth factor family: identification of a fourth molecular species and characterization of alternative splicing of RNA. Mol Endocrinol. 1991; 5:1806-1814.

15. Ferrara N, Henzel WJ. Pituitary follicular cells secrete a novel heparin-binding growth factor specific for vascular endothelial cells. Biochem Biophys Res Commun. 1989; 161:851-858.

16. Park DJ, Thomas NJ, Yoon C, Yoon SS. Vascular endothelial growth factor a inhibition in gastric cancer. Gastric Cancer. 2015; 18:33-42.

17. Mihalache A, Rogoveanu I. Angiogenesis factors involved in the pathogenesis of colorectal cancer. Curr Health Sci J. 2014; 40:5-11.

18. Goel HL, Mercurio AM. VEGF targets the tumour cell. Nat Rev Cancer. 2013; 13:871-882.

19. Alevizakos M, Kaltsas S, Syrigos KN. The VEGF pathway in lung cancer. Cancer Chemother Pharmacol. 2013; 72:1169-1181.

20. NCCN Guideline:http://www.nccn.org/professionals/physician_gls/pdf/colon.pdf

21. LeCouter J, Kowalski J, Foster J, Hass P, Zhang Z, Dillard-Telm L, Frantz G, Rangell L, DeGuzman L, Keller GA, Peale F, Gurney A, Hillan KJ, et al. Identification of an angiogenic mitogen selective for endocrine gland endothelium. Nature. 2001; 412:877-884.

22. Nagano H, Goi T, Koneri K, Hirono Y, Katayama K, Yamaguchi A. Endocrine gland-derived vascular endothelial growth factor (EG-VEGF) expression in colorectal cancer. J Surg Oncol. 2007; 96:605-610.
23. Goi T, Fujioka M, Satoh Y, Tabata S, Koneri K, Nagano H, Hirono Y, Katayama K, Hirose K, Yamaguchi A. Angiogenesis and tumor proliferation/metastasis of human colorectal cancer cell line SW620 transfected with endocrine glands-derived-vascular endothelial growth factor, as a new angiogenic factor. Cancer Res. 2004; 64:1906-1910.

24. Tabata S, Goi T, Nakazawa T, Kimura Y, Katayama K, Yamaguchi A. Endocrine gland-derived vascular endothelial growth factor strengthens cell invasion ability via prokineticin receptor 2 in colon cancer cell lines. Oncol Rep. 2013; 29:459-463.

25. Jiang X, Abiatari I, Kong B, Erkan M, De Oliveira T, Giese NA, Michalski CW, Friess H, Kleeff J. Pancreatic islet and stellate cells are the main sources of endocrine gland-derived vascular endothelial growth factor/prokineticin-1 in pancreatic cancer. Pancreatology. 2009; 9:165-172.

26. Ngan ES, Sit FY, Lee K, Miao X, Yuan Z, Wang W, Nicholls JM, Wong KK, Garcia-Barcelo M, Lui VC, Tam PK. Implications of endocrine gland-derived vascular endothelial growth factor/prokineticin-1 signaling in human neuroblastoma progression. Clin Cancer Res. 2007; 13:868-875.

27. Pasquali D, Rossi V, Staibano S, De Rosa G, Chieffi P, Prezioso D, Mirone V, Mascolo M, Tramontano D, Bellastella A, Sinisi AA. The endocrine-gland-derived vascular endothelial growth factor (EG-VEGF)/prokineticin 1 and 2 and receptor expression in human prostate: up-regulation of EG-VEGF/prokineticin 1 with malignancy. Endocrinology. 2006; 147:4245-4251.

28. Morales A, Vilchis F, Chávez B, Chan C, Robles-Díaz G, Díaz-Sánchez V. Expression and localization of endocrine gland-derived vascular endothelial growth factor (EG-VEGF) in human pancreas and pancreatic adenocarcinoma. J Steroid Biochem Mol Biol. 2007; 107:37-41.

29. Hanahan D, Weinberg RA. Hallmarks of cancer: the next generation. Cell. 2011; 144:646-674.

30. Findlay VJ, Wang C, Watson DK, Camp ER. Epithelial-tomesenchymal transition and the cancer stem cell phenotype: insights from cancer biology with therapeutic implications for colorectal cancer. Cancer Gene Ther. 2014; 21:181-187.

31. Welti J, Loges S, Dimmeler S, Carmeliet P. Recent molecular discoveries in angiogenesis and anti-angiogenic therapies in cancer. J Clin Invest. 2013; 123:3190-3200.

32. Shojaei F. Anti-angiogenesis therapy in cancer: current challenges and future perspectives. Cancer Lett. 2012; 320:130-137.

33. De Vries C, Escobedo JA, Ueno H, Houck K, Ferrara N, Williams LT. The fms-like tyrosine kinase, a receptor for vascular endothelial growth factor. Science. 1992; 255:989-991.

34. Shibuya M, Yamaguchi S, Yamane A, Ikeda T, Tojo A, Matsushime H, Sato M. Nucleotide sequence and expression 
of a novel human receptor-type tyrosine kinase gene (flt) closely related to the fms family. Oncogene. 1990; 5:519-524.

35. Terman BI, Dougher-Vermazen M, Carrion ME, Dimitrov D, Armellino DC, Gospodarowicz D, et al. Identification of the KDR tyrosine kinase as a receptor for vascular endothelial cell growth factor. Biochem Biophys Res Commun. 1992; 187:1579-1586.

36. Ke Q1, Costa M. Hypoxia-inducible factor-1 (HIF-1). Mol Pharmacol. 2006; 70:1469-1480.

37. Monnier J, Samson M. Prokineticins in angiogenesis and cancer. Cancer Lett. 2010; 296:144-149.
38. UICC International Union Against Cancer. "TNM Classificationof Malignant Tumours. Seventh" Edition. Wiley-Blackwell; 2009.

39. Japanese Society for Cancer of the Colon and Rectum: Japanese Classification of Colorectal Carcinoma. 1st English edition. Tokyo: Kanehara, 1997.

40. Goi T, Nakazawa T, Hirono Y, Yamaguchi A. The antiprokineticin1(PROK1) monoclonal antibody suppresses angiogenesis and tumor growth in the colorectal cancer. Ann Surg Oncol. 2014; 21:665-671. 